\title{
Determination of Trace Amounts of Boron in Steels by On-line Reaction/ Concentration/Separation Using an Anion-exchange Column
}

\author{
Chaoying SHaO*广 and Kazuhisa YoshIMURA** \\ *College of Chemistry, Chemical Engineering and Biotechnology, Donghua University, Shanghai 201620, \\ P. R. China \\ **Department of Chemistry, Faculty of Sciences, Kyushu University, Hakozaki, Fukuoka 812-8581, Japan
}

\begin{abstract}
A method for the on-line absorptiometric determination of trace amounts of boron in steels was developed using an anion-exchange column presorbed with chromotropic acid. The on-line reaction and separation were achieved by controlling the $\mathrm{pH}$ in order to accelerate the complex formation in the column by 2.7 and to stabilize the complex at $\mathrm{pH} 8$ for the selective elution of a 1:2 complex and its detection at $350 \mathrm{~nm}$. The effects from the iron matrix in the sample were effectively removed by using EDTA as a masking agent; a low limit for boron detection $(3 \sigma)$ of $0.04 \mu \mathrm{g} \mathrm{g}^{-1}$ was obtained.
\end{abstract}

(Received June 25, 2010; Accepted January 17, 2011; Published March 10, 2011)

\section{Introduction}

The concentration of boron in steels must be kept within a definite range because too high a boron content causes difficulties in malleability and ductility, although it is necessary for hardenability. Therefore, it is important to monitor boron in steels because of its significant influence on the steel's characteristics. Although inductively coupled plasma-mass spectrometry (ICP-MS) is the most sensitive analytical technique for trace multi-elements, the measurement for boron suffers from serious matrix interferences and memory effects, which lead to a decrease in its sensitivity and accuracy. Some chemicals, such as mannitol, fluoride and ammonia, have been used for eliminating the memory interferences. ${ }^{1-4}$ A flow-injection system with extraction treatment has also been coupled with ICP-MS to remove the effects of sample matrices for the determination of sub- $\mu \mathrm{g} \mathrm{g}^{-1}$ levels of boron in iron and steel. ${ }^{5}$

On the other hand, the high-performance liquid chromatography (HPLC) methods with a spectrophotometric or a fluorometric detector have been proposed for determining boron in steels. ${ }^{6-10}$ However, the processes of special separation and/or preconcentration were often used to improve the detection sensitivity. ${ }^{10-12}$ The standard methods for the determination of boron in iron and steel based on JIS are also spectrophotometries including a distillation or extraction procedure for samples with a boron content greater than $2 \mu \mathrm{g} \mathrm{g}^{-1}$. $^{13}$

Increasing attention has been paid to the HPLC system, which can be extended to develop an integrated analytical device involving simultaneous preconcentration/separation and detection. ${ }^{10}$ In our previous studies on the complexation of boric acid with chromototropic acid (4,5-dihydroxy-2,7naphthalene disulfonic acid), an on-line UV absorptiometric system for the 1:2 complex was designed using an anion-exchange column and successfully applied to the

† To whom correspondence should be addressed.

E-mail: shaocy@dhu.edu.cn determination of ultra-trace amounts of boron in water. ${ }^{14}$ In this study, the applicability of our method to the determination of trace amounts of boron in steel was examined.

\section{Experimental}

Reagents and chemicals

All chemicals were of analytical or guaranteed grade. Deionized water prepared by a Milli-Q SP system (Millipore, MA) was used throughout. All solutions were stored in vessels made from polyethylene or PTFE.

The standard boron solution $\left(1000 \mathrm{mg} \mathrm{dm}^{-3}\right)$ was a Wako (Osaka, Japan) product. Chromotropic acid (disodium salt, dehydrate) was obtained from Dojin (Kumamoto, Japan), and was used without further purification. A buffer solution ( $1 \mathrm{~mol} \mathrm{dm}^{-3}$ formic acid-ammonium formate solution, $\mathrm{pH}$ 2.7) and a masking solution containing $0.5 \mathrm{~mol} \mathrm{dm}^{-3}$ ethylenediamine tetraacetic acid (EDTA, disodium salt) were prepared for use as the reagent solution and carrier solution. A reagent solution $\left(0.002 \mathrm{~mol} \mathrm{dm}^{-3}\right.$ of chromotropic acid) was prepared by dissolving $80 \mathrm{mg}$ of chromotropic acid in a mixture of $1 \mathrm{~cm}^{3}$ of the buffer solution and $0.2 \mathrm{~cm}^{3}$ of the masking solution before diluting to $100 \mathrm{~cm}^{3}$ with water. The solution could be used for 10 days when stored in a refrigerator.

A carrier solution was made by diluting a mixture of $10 \mathrm{~cm}^{3}$ of the buffer solution and $0.2 \mathrm{~cm}^{3}$ of the masking solution up to $1 \mathrm{dm}^{3}$ with water. An eluent $\left(0.2 \mathrm{~mol} \mathrm{dm}^{-3}\right.$ or $0.5 \mathrm{~mol} \mathrm{dm}^{-3}$ sodium perchlorate solution) containing $0.001 \mathrm{~mol} \mathrm{dm}^{-3}$ 2-[4-(2-hydroxyethyl)-1-piperazinyl]ethanesulfonic acid (HEPES, adjusted at $\mathrm{pH} 8$ ) was used for stepwise elution of the free reagent and the 1:2 complex.

\section{Apparatus}

Absorbance measurements were made by a JASCO U-best 35 UV-Vis double-beam spectrophotometer (Nippon Bunko, Tokyo, Japan) equipped with a flow cell of $1.5 \mathrm{~mm}$ diameter and $1 \mathrm{~cm}$ length (GL Science, Tokyo, Japan). A Pantos U-228 


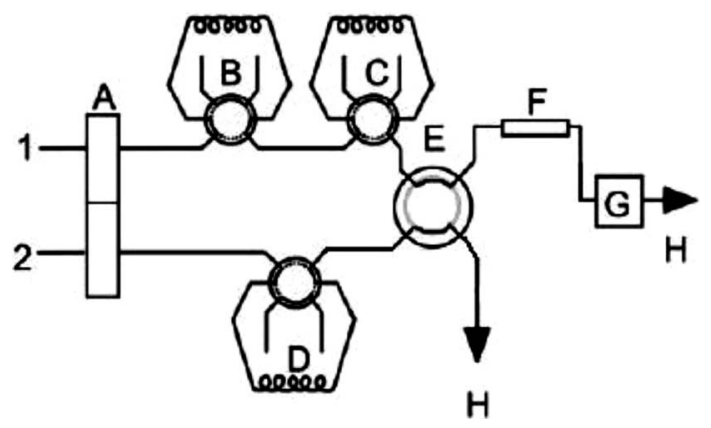

Fig. 1 Schematic flow system diagram. (1) Carrier solution, $0.01 \mathrm{~mol} \mathrm{dm}^{-3}$ formate buffer; flow rate, $0.65 \mathrm{~cm}^{3} \mathrm{~min}^{-1}$. (2) Eluent solution, $0.2 \mathrm{~mol} \mathrm{dm}^{-3} \mathrm{NaClO}_{4}$; flow rate, $0.95 \mathrm{~cm}^{3} \mathrm{~min}^{-1}$. (A) Pumps. (B) PTFE six-way rotary valve for introducing the reagent solution. (C) PTFE six-way rotary valve for sample introduction. (D) PTFE six-way rotary valve for introducing the eluent solution $\left(0.5 \mathrm{~mol} \mathrm{dm}^{-3}\right.$ $\mathrm{NaClO}_{4}$ ). (E) PTFE double four-way valve. (F) anion-exchanger column. (G) Spectrophotometer. (H) Waste.

recorder (Nippon Denshi Kagaku, Kyoto, Japan) was used for recording the chromatograms.

\section{Flow diagram}

A flow diagram of the HPLC system is shown in Fig. 1. The system consisted of two streams, one for introducing the reagent and the samples at $\mathrm{pH} 2.7$ (1), and the other for separating the 1:2 complex from the column at $\mathrm{pH} 8$ (2). The solutions were pumped by double-plunger micropumps (SNK DMX-2000, Tokyo, Japan) (A) and the flow rate was $0.65 \mathrm{~cm}^{3} \mathrm{~min}^{-1}$ for the carrier stream and $0.95 \mathrm{~cm}^{3} \mathrm{~min}^{-1}$ for the eluent stream. The reagent (B), sample (C) and the eluent $\left(0.5 \mathrm{~mol} \mathrm{dm}^{-3}\right.$ sodium perchlorate) (D) solutions were introduced into the streams by means of separate six-way rotary valves connected with PTFE tube loops. An anion-concentration column (IonPac AC10, $4 \mathrm{~mm}$ i.d., $5 \mathrm{~cm}$ long) (F) from Dionex Corp. (CA), which was thermostated at $45^{\circ} \mathrm{C}$ in a water bath, was used.

\section{Sample preparation}

To $0.1 \mathrm{~g}$ of a sample weighed in a $25-\mathrm{cm}^{3}$ fused silica vessel, $2 \mathrm{~cm}^{3}$ of the concentrated hydrochloric acid and $1 \mathrm{~cm}^{3}$ of the concentrated nitric acid were added. After digestion at room temperature, the mixture was mildly heated to completely decompose the sample; $4 \mathrm{~cm}^{3}$ of the 1:1 phosphoric acid and $2 \mathrm{~cm}^{3}$ of the 1:1 sulfuric acid were then added and the solution was heated until sulfuric acid fumes appeared, and the temperature was maintained at $290^{\circ} \mathrm{C}$ for $30 \mathrm{~min}$. The residue was dissolved in water and diluted to $100 \mathrm{~cm}^{3}$ in a flask.

To $10 \mathrm{~cm}^{3}$ of the decomposed sample solution, $1.5 \mathrm{~cm}^{3}$ of the masking solution and $5 \mathrm{~cm}^{3}$ of the formic acid buffer were added. The $\mathrm{pH}$ of the solution was adjusted to 2.7 with a small amount of $2.5 \mathrm{~mol} \mathrm{dm}^{-3}$ sodium hydroxide solution, and then the solution was diluted up to $50 \mathrm{~cm}^{3}$ for measurements.

\section{Measurement}

Into the carrier stream, $0.5 \mathrm{~cm}^{3}$ of the reagent solution was first introduced through the six-way rotary valve B (Fig. 1). Next, $5.0 \mathrm{~cm}^{3}$ of the sample solution was introduced into the stream through the six-way rotary valve C. An eluent solution of $0.2 \mathrm{~mol} \mathrm{dm} \mathrm{dm}^{-3}$ sodium perchlorate was then pumped through the column by switching the four-way valve, E, to elute the excess reagent and the components with lower anion charges. Finally, $0.5 \mathrm{~mol} \mathrm{dm}^{-3}$ of the sodium perchlorate solution was

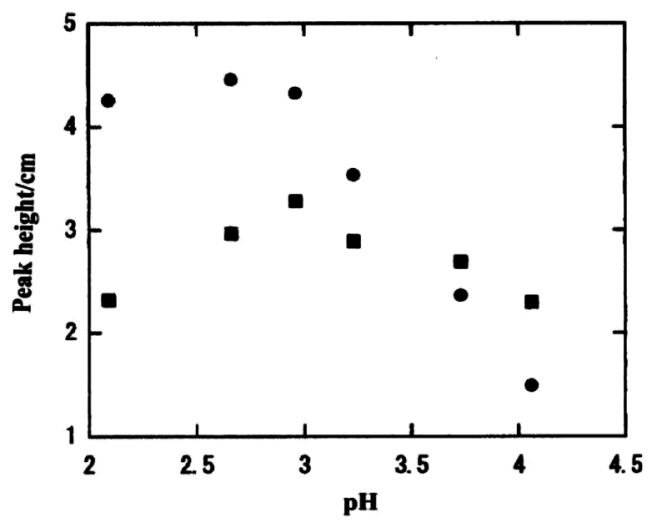

Fig. 2 Peak heights for the 1:2 complex determined with an IonPac AC10 column $(\mathbf{O})$ and a TSK gel IC-Anion-PW column (ם) under different $\mathrm{pH}$ conditions. Chromotropic acid, $1 \mu \mathrm{mol}$; boric acid, $7.3 \times 10^{-7} \mathrm{~mol} \mathrm{dm}{ }^{-3}, 5 \mathrm{~cm}^{3} ; 45^{\circ} \mathrm{C}$; flow rate, $0.65 \mathrm{~cm}^{3} \mathrm{~min}^{-1}$; full scale, $0.5 \mathrm{AU}(25 \mathrm{~cm}$ on the chart).

introduced into the column through the six-way rotary valve D and the 1:2 complex was eluted. The absorbance at $350 \mathrm{~nm}$ was continuously monitored and the height of the complex peak in the chromatogram was employed for the quantitative determination of boron.

\section{Results and Discussion}

Establishment of an on-line reaction/concentration/separation system for boron determination

The 1:1 complexation of boron with chromotropic acid quickly proceeds, but the 1:2 complexation is thermodynamically and kinetically controlled. ${ }^{15}$ The kinetic factors play a decisive role in the on-line determination of trace levels of boron. The conditions of sufficient hydrogen ions as a catalyst and a large excess of the chromogenic agent are required for fast complex formation during the reaction. This has been satisfactorily solved in our system ${ }^{14}$ by presorbing chromotropic acid on an anion-exchange column where the reagent concentration was higher than that in the solution. The on-line reaction with boric acid was accomplished only by flowing the sample solution through the column under a lower $\mathrm{pH}$ condition.

For the on-line determination of trace amounts of boron in steels, interferences from the iron matrix could be removed in the presence of EDTA, since the iron complex with EDTA was not adsorbed on the column under the acidic conditions. The $\mathrm{pH}$ value for the complexation was set at 2.7 , and the complex was successfully separated from the excess reagent and other components with low anion charges by stepwise elution procedures employing $0.2 \mathrm{~mol} \mathrm{dm}^{-3}$ and $0.5 \mathrm{~mol} \mathrm{dm}^{-3} \mathrm{NaClO}_{4}$ eluents at $\mathrm{pH} \mathrm{8}$, at which point the decomposition of the 1:2 complex is very slow to carry out. ${ }^{15}$

\section{Optimization for the column reaction}

The kinetics for the 1:2 complexation of boric acid with chromotropic acid within a column is mainly influenced by the following factors: the concentration of chromotropic acid on the column, residence time for the sample flowing through the adsorption band of the reagent on the column, $\mathrm{pH}$ conditions, and column characteristics. The efficiency of the on-line complexation was investigated using a series of anion-exchange columns, i.e., TSK gel IC-Anion-PW (4.6 mm i.d., $5 \mathrm{~cm}$ long, 


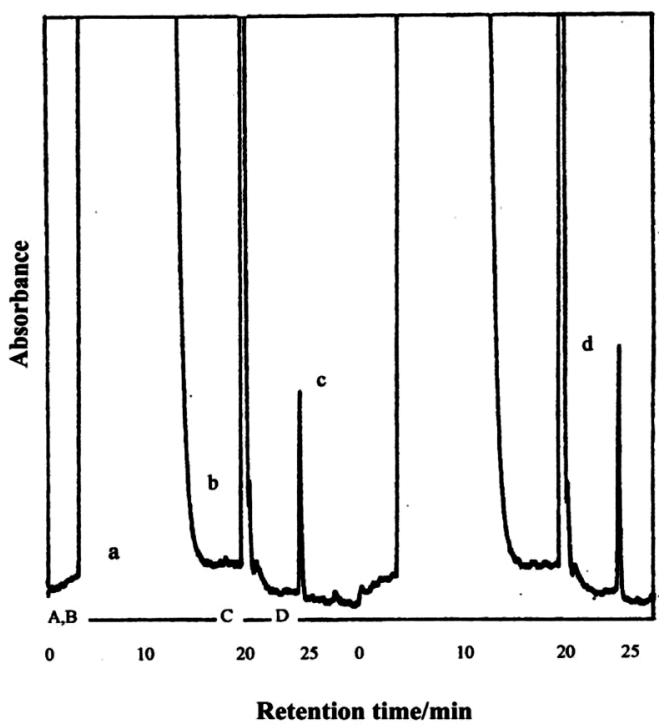

Fig. 3 Typical chromatogram of a steel sample. A, Introducing a chromotropic acid reagent; $\mathrm{B}$, introducing a sample solution; $\mathrm{C}$, eluting with $0.2 \mathrm{~mol} \mathrm{dm}^{-3} \mathrm{NaClO}_{4}$; D, eluting with $0.5 \mathrm{~mol} \mathrm{dm}^{-3}$ $\mathrm{NaClO}_{4}$. a, Fe-EDTA complex; b, free chromotropic acid; c, 1:2 complex for the sample of JSS 362-1; d, 1:2 complex for the sample of JSS $362-1$ to which $2 \mu \mathrm{g} \mathrm{B} \mathrm{dm}{ }^{-3}$ was added.

Tosoh, Tokyo, Japan), TSK gel IC-Anion-PW $\mathrm{XL}_{\mathrm{XL}}$ (4.6 mm i.d., $3.5 \mathrm{~cm}$ long, Tosoh), IonPac AC10 (4 mm i.d., $5 \mathrm{~cm}$ long, Dionex) and IonPac TAC-2 (3 mm i.d., $3.5 \mathrm{~cm}$ long, Dionex). The respective Dionex anion-concentrator columns, packed with the support beads of $8.5 \mu \mathrm{m}$ and $30 \mu \mathrm{m}$ in diameter on which 160 and $250 \mathrm{~nm}$ in diameter latex ion exchangers were coated, having total exchange capacities of 4.0 and $3.4 \mu \mathrm{eq},{ }^{16,17}$ which are lower than those of the TSK columns, whose capacities are $24.9 \mu \mathrm{eq}$ and $17.4 \mu$ eq. ${ }^{18}$ Among them, the IonPac AC10 anion-concentration column had the highest sensitivity for the determination of boron due to its lower ion-exchange capacity in unit column volume, because chromotropic acid would be held with a longer adsorption band compared to that of the other columns. The thinner coating of the latex ion exchangers might also be favorable for on-line complexation. Moreover, the IonPac AC10 column packed with the smaller ion-exchanger beads had more theoretical plates, while those in the TSK columns were almost the same (1000 - 1100 for sulfate).

The optimum $\mathrm{pH}$ condition for the on-line determination of boron using the IonPac AC10 column appeared in the lower $\mathrm{pH}$ range, and the sensitivity quickly decreased with increasing $\mathrm{pH}$ of the medium (Fig. 2). For a comparison, the $\mathrm{pH}$ dependence of the complex formation using the TSK gel IC-Anion-PW column is also shown in Fig. 2. By taking the reaction efficiency and the effectiveness of the masking agent into consideration, the $\mathrm{pH}$ condition for the on-line complexaction on the IonPac AC10 column was selected to be 2.7. A higher temperature and a lower flow rate are favorable, but we selected a temperature of $45^{\circ} \mathrm{C}$ and a flow rate of $0.65 \mathrm{~cm}^{3} \mathrm{~min}^{-1}$ for practical use. It is obvious that the increase in the contents of chromotropic acid adsorbed on the column is advantageous for on-line complex formation, but a longer time is needed to elute any large excess of the reagent after the reaction, and therefore $1 \mu \mathrm{mol}$ of the reagent was introduced into the column.
Table 1 Determination of boron in steels ${ }^{\mathrm{a}}$

\begin{tabular}{ccc}
\hline \multirow{2}{*}{ Sample } & \multicolumn{2}{c}{ Concentration $/ \mu_{\mathrm{g} \mathrm{g}}{ }^{-1}$} \\
\cline { 2 - 3 } & Proposed method & Certified value $^{\mathrm{b}}$ \\
\hline JSS 361-1 & $9.1 \pm 0.2$ & 9 \\
JSS 362-1 & $18.2 \pm 0.1$ & 18 \\
JSS 363-1 & $26.6 \pm 0.8$ & 27 \\
JSS 364-1 & $45.2 \pm 1.2$ & 45 \\
\hline
\end{tabular}

a. Mean for triplicate measurements.

b. Certified by the Japanese Iron and Steel Institute.

\section{Removal of the coexisting metal ions}

The interferences to the boron determination mainly come from any coexisting metals in the sample, which react with the reagent under the experimental conditions and/or absorb the radiation around $350 \mathrm{~nm}$. Iron reacts with chromotropic acid to form a complex absorbing violet radiation. The effects from large amounts of iron and other metal ions could effectively be removed by using EDTA as a masking agent. By adding 3-times the amount of EDTA relative to that of the iron, the coexisting ions were completely suppressed, and the Fe-EDTA complex, showing an absorption at around $350 \mathrm{~nm}$, was easily eluted from the column without any disturbance to the on-line determination of the trace amounts of boron (Fig. 3).

\section{Optimization for elution}

It was experimentally demonstrated that a $\mathrm{NaClO}_{4}$ solution equal or higher than $0.25 \mathrm{~mol} \mathrm{dm}{ }^{-3}$ was required for desorbing the 1:2 complex from the IonPac AC10 column. Thus, chromatographic separation was performed by the stepwise elution procedures to eliminate any interferences from the free reagent and other anions. After the excess reagent and the components with lower anion charges were removed using a $0.2 \mathrm{~mol} \mathrm{dm}^{-3} \mathrm{NaClO}_{4}$ solution, the complex was satisfactorily eluted with $0.5 \mathrm{~mol} \mathrm{dm}^{-3}$ of the eluent to obtain a sharp elution peak for the measurement (Fig. 3).

\section{Determination of steel samples}

Standard steel samples for boron determination made at the Japanese Iron and Steel Institute as JSS 361-1, JSS 362-1, JSS 363-1 and JSS 364-1 were used to test the applicability of the proposed method. Figure 3 shows a typical chromatogram for the boron determination of the JSS 362-1 sample. Obviously, the 1:2 complex presented a sharp elution peak, and was affected neither by the matrices nor the excess reagent. The analytical results of standard samples for triplicate measurements are listed in Table 1.

The precision of the method was evaluated using sample JSS 362-1. The mean concentration of boron for five replicate measurements was $18.2 \pm 0.6 \mu \mathrm{g} \mathrm{g}^{-1}$, which gave an RSD of $3 \%$. In order to check the reliability of the method, a sample of JSS 363-1 was determined for different dilutions. A good linear relation for the complex peak height to the sample volume clearly indicated that there were no interferences in the actual measurements.

The concentrations of boron in the standard steel samples obtained by the present method were compared with the certified results. As can be seen in Table 1, they agree very well. The accuracy of the detection was also examined by determining boron using the standard-addition method. The slopes for the standard-addition curves were in good agreement with that of the calibration made using the standard boron solution. 
The limit of detection for the proposed method, defined as the standard deviation of the blank signals $(3 \sigma)$, was $0.04 \mu \mathrm{g} \mathrm{g}^{-1}$ for boron $(n=4)$ for the recommended procedure. This value is almost the same as that obtained by an isotope-dilution ICP-MS measurement with an off-line matrix removal treatment $\left(0.02 \mu \mathrm{g} \mathrm{g}^{-1}\right) .{ }^{5}$ Also, the detection limit can be further lowered by introducing a larger volume of the sample solution, as mentioned in our earlier report. ${ }^{14}$

Overall, the proposed method can be used to determine trace amounts of boron with high precision and accuracy in steel samples.

\section{Acknowledgements}

We thank Dr. Kyoko Fujimoto of the JFE Steel Corporation, Tosoh Corporation and Kurita Corporation, for the kind donations of the standard materials and the anion-exchange columns.

\section{References}

1. W.-C. Wei, C.-J. Chen, and M.-H. Yang, J. Anal. At. Spectrom., 1995, 10, 955.

2. A. Makishima, E. Nakamura, and T. Nakano, Anal. Chem., 1997, 69, 3754.

3. A. Al-Ammar, R. K. Gupta, and R. M. Barnes, Spectrochim. Acta, Part B, 1999, 54, 1077.

4. D.-H. Sun, R.-L. Ma, C. W. McLeod, X.-R. Wang, and A. G. Cox, J. Anal. At. Spectrom., 2000, 15, 257.
5. A. G. Coedo, T. Dorado, B. J. Fernandez, and F. J. Alguacil, Anal. Chem., 1996, 68, 991.

6. S. Motomizu, S. Sawatani, M. Oshima, and K. Toei, Anal. Chem., 1983, 55, 1629.

7. Z. Jun, M. Oshima, and S. Motomizu, Bunseki Kagaku, 1988, 37, T228.

8. K. Uesawa, N. Uehara, K. Ito, and T. Shimizu, Bunseki Kagaku, 2001, 50, 867.

9. N. Uehara, K. Yamaguchi, and T. Shimizu, Anal. Sci., 2001, 17, 1421.

10. T. Yamane, Y. Kouzaka, and M. Hirakawa, Talanta, 2001, $55,387$.

11. K. Toei, S. Motomizu, M. Oshima, and H. Wateri, Analyst, 1981, 106, 776.

12. M. Hosoya and M. Takeuchi, Bunseki Kagaku, 1986, 35, 854.

13. JIS G1227, "Methods for Determination of Boron in Iron and Steel", 1992, Japanese Industrial Standards Committee, Tokyo.

14. C. Shao, S. Matruoka, Y. Miyazaki, and K. Yoshimura, Analyst, 2002, 127, 1614.

15. C. Shao, S. Matruoka, Y. Miyazaki, K. Yoshimura, T. M. Suzuki, and D. A. P. Tanaka, J. Chem. Soc., Dalton Trans., 2000, 3136.

16. Dionex Corp., Product Manual, IonPac Trace Anion Concentrator (TAC-2) Column, No. 34467, 2004.

17. Dionex Corp., Product Manual, IonPac AC10 Concentrator Column, No. 34529, 2002.

18. Tosoh Corp., TSK-GEL IC Column, http://www.separations. asia.tosohbioscience.com/. 